\title{
A Call for Conscious Changes to Counter COVID-19
}

\author{
Cornelia C. Walther ${ }^{1}$ (D)
}

Received: 30 October 2020 / Accepted: 11 February 2021 / Published online: 21 May 2021

(c) The Author(s), under exclusive licence to Springer Nature Switzerland AG 2021

\begin{abstract}
This article lays out the contours of a novel approach to social change and interactions, based on the organic interplay of individuals, institutions, countries and the global society. This approach is based on the POZE paradigm, which posits that change starts inside and is nurtured from the outside in - both for individuals and for durable social change. Such a holistic perspective is crucial to build society as it emerges from the Pandemic. COVID-19 is a reminder that humans around the World are fundamentally all the same; the result of 4 dimensions - soul, heart, mind and body, which find their expression in aspirations, emotions, thoughts and sensations. These 4 dimensions constantly interact and influence each other in ways that reflect the 4-dimensional dynamic that shapes our collective existence. Individuals are the micro dimension that stands at the center of everything else. Forming part of various institutions, from families to parties, individuals are constitutive components of the meso dimension. Individuals and institutions form countries and economies, the macro-dimension. These dimensions in addition to nature and supra-national institutions form the meta-dimension. A constant interplay connects and determines what happens in each dimension and what derives from it. To thrive in the post-pandemic world, we must understand and optimize this interplay. This is the point of departure for the argumentation laid out in this article. The prevailing systemic imbalance in which many lack the means to cover their basic needs can only be addressed by planting the $C$-Core (completion, compassion, creativity, cooperation) at the center of human interactions. When we bring risks, responsibility and real opportunities together in one coherent framework whilst applying the proposed twice 4-dimensional paradigm-shift a set of concrete recommendations appears. Looking at individuals, and institutions, the article concludes with suggestions to seize this moment and shape not merely a response to the crises, but to lay the ground for a new social contract. In the past the $\mathrm{C}$ in C-Suite stood for Chief, the upper part of the leadership ladder in an institution. In the future that $\mathrm{C}$ must represent $\mathrm{C}$-Core qualities.
\end{abstract}

Cornelia C. Walther cornelianow@hotmail.com

1 POZE, Tuebingen, Germany 
Keywords Pandemic · Paradigm - Transition - Transformation · Aspirations · Emotions $\cdot$ Experience $\cdot$ Behavior $\cdot$ Planet $\cdot$ Dynamic $\cdot$ System $\cdot$ Influence $\cdot$ POZE - Aid - Development - Continuum - Thought $\cdot$ Sensation $\cdot$ P-Puzzle . C-Core COVID-19 · Community · Institution · Conundrum · Complementarity · Cooperation $\cdot$ Connection $\cdot$ Glocal $\cdot$ Localization $\cdot$ Pandemic $\cdot$ Solidarity $\cdot$ Optimization $\cdot$ Purpose $\cdot$ Zeal $\cdot$ Soul $\cdot$ Heart $\cdot$ Mind $\cdot$ Body $\cdot$ Change $\cdot$ Inspiration . Micro $\cdot$ Meso $\cdot$ Macro $\cdot$ Meta $\cdot$ Creativity $\cdot$ Compassion

\section{Introduction}

COVID-19 is a reminder that humans around the World are fundamentally all the same; the result of 4 dimensions - soul, heart, mind and body, which find their expression in aspirations, emotions, thoughts and sensations. The unfolding situation may either serve as a social equalizer, because it affects people independently of their passport, income, skin color, gender, and skills, or it may cultivate a groundswell of drastic disconnection. Individuals and institutions are affected in different, mutually reinforcing ways by the Pandemic and the measures to contain it. We will look at both spheres briefly to set the stage for what follows.

Inequality has become the unspoken marching theme of 2020, "because now, in the era of the virus, a poor person's sickness can affect a wealthy society's health.” (Roy, 2020). COVID-19 does not discriminate between those who get infected. Up and down the ladder of wealth, across nations and literacy levels, people fall sick, some of them fatally. This context is prone to panic and fear, to isolation and xenophobia. But the experience that sick people and their families go through depend on biology, paycheck and location. If you are poor, old, afflicted by chronic illness, and/or live in a low-income country your chances to get severely sick and die are significantly heightened, while the likelihood of quality health care diminishes dramatically.

The universality of impact coupled with the unequal chances of survival illustrates the systemic social paradox of inequities that has shaped our collective existence for centuries. Addressing this paradox, which may appear like a gordian knot begins at the core of the center, with the smallest entity of our collective existence. Solving the conundrum that COVID-19 has placed in our hands begins with the aspiration of individuals for meaning.

Individual wellbeing conditions social welfare, and vice-versa. One without the other is unsustainable. Anchored in this perspective the paradigm-shift presented in this article (POZE) offers a multidimensional perspective that can be used to understand and promote social change, via personal transformation and vice-versa. It is based on the understanding that change starts from the inside out and is nurtured from the outside in. ${ }^{1}$

\footnotetext{
1 The symmetry that underpins the POZE paradigm is reflected in its methodology. It connects the different stages of personal change (awareness, acceptance, alignment, accountability) to the 4 pillars of social transformation (perspective, optimization, zenith, exposure). These two sets of elements mirror the 4 dimensions of every individual (soul, heart, mind, body) which relate to 4 complementary values that matter for sustainable change (generosity, compassion, honesty, courage). This overall logic is the underpinning of the C-Core (individual) and the P-Puzzle (institution) (Walther, 2020c).
} 
Individuals who not only know what they want for themselves, and for their community; but who are ready to invest their energy, their action and assets to make it happen, influence what happens next. There are, and always have been, many factors that are out of our control. COVID-19 brutally reminded us that whatever illusion of homeostasis we had, was nothing more than a temporary grip on a glitchy, morphing, dissolving and ever revolving reality - which is by its own nature out of control. We do not rule the meso, macro and meta dimensions that we are part of. But what we do and who we are influences what happens in the dimension that we represent, hereby impacting the other dimensions that we co-constitute. This may seem contradictory, but it is not. The following offers a multidimensional perspective that can be used to understand and promote social change, via personal transformation and vice-versa.

POZE looks at individual existence as a composition of 4 dimensions (soul, heart, mind, body) expressed as aspirations, emotions, thoughts and sensations. This makes each individual a micro mirror of the society they constitute, which is a composition of individuals, communities, countries and - together with nature, planet Earth. Whatever happens in one dimension influences the others. Adopting this twice 4-dimensional perspective makes universal 'quality of life' (Michalos, 2017) a pragmatic undertaking, which begins at the core of the center - the aspiration of individuals, for meaning.

Everything is connected. Though we do not have control over the whole game, the way in which we choose to move our tokens impacts the experience and behavior of other players; which has an outcome on the match. At this stage we do not know when enough vaccines will be available for everyone, nor do we have longterm data on its efficiency and effectiveness. We do not know how long it takes to vaccinate how many people, thus we are unsure how long the containment measures will remain in place and how strictly physical distancing regulations will be maintained in the future. As this article goes into publishing we are floating in a limbo, between a yesterday that is gone and a tomorrow that has not arrived yet. What follows here is a description of two concepts to unpack the social conundrum that our present and future have become. The $C$-Core presented in this article entails a set of mindshifts for individuals. It covers the quest for Completion which relates to the pursuit of the best version of our individual and collective self; Compassion for oneself and others; Creativity or the ability to go beyond the known and tested to discover radically new solutions that match the reality of a post-pandemic world; and Cooperation with a wide range of players in a perspective that maximizes the resources of all parties. The P-Puzzle, also presented here, applies this logic to institutions. It distills organizations in the components that influence their internal and external operating mode - Priorities, People, Positions and Programs. Both are anchored in POZE, which considers individual wellbeing as the cause and consequence of social transformation; or the understanding that social change happens from the inside out and is nurtured from the outside in. ${ }^{2}$

\footnotetext{
2 The POZE methodology encompasses, among other elements, Purpose for Power (P4P), Compassion for Change (C4C), Honesty for Humility $(\mathrm{H} 4 \mathrm{H})$ and influence for impact (i4i). Starting 2017 in Haiti it has expanded into the Americas and Europe. For further details on the approach please see Walther (2020a, b, c).
} 
Following a brief introduction in the philosophical set-up that underpins the context created by COVID-19 (this "Introduction" section), this article presents the logic of a holistic, radically different take on the multidimensional reality that shapes who we are and become, individually and collectively ("Contextualizing a Post-Pandemic World"). This sets the stage for a new perspective on institutions, with the P-Puzzle to analyze the components that matter in the endeavor of shaping organizational cultures that are conducive to global solidarity ("Concepts"). ${ }^{3}$ Based on the $C$-Core we lay out a set of recommendations to live in a world that is interdependent, interconnected and influenced by intrapersonal choices. Mind-shifts in line with the $C$-Core can be taken by anyone anywhere with benefit to the individuals who make them and the environment they evolve in. This perspective is particularly relevant as a complement of the classic C-Suite. ${ }^{4}$ It emphasizes that genuine leadership is not about chiefs' titles and privileges, but relates to the human qualities that are expressed by individuals at their respective levels ("Perspectives"). We conclude with a possible way forward and out of the COVID conundrum ("Soliciting Solutions. A Way Forward").

\section{Contextualizing a Post-Pandemic World}

This section gives an overview of the post-Pandemic context, including some of the challenges and opportunities that derive from it.

COVID-19 raised the curtain on an imbalance that has been condoned for centuries. The Pandemic illustrates a systemic social paradox, because every single person on the planet is at risk of infection. However, the exposure to that risk, and the impact of the Virus, as well as the measures to contain it, depend on the income, profession, and location of the individual. Unless we seize the challenge that COVID-19 has placed in our hands as an opportunity to finally design a social system that addresses the needs and resources of everybody, the perspectives are gloomy, for everyone.

\footnotetext{
3 In the context of this article we refer to 'Solidarity' as an awareness of shared interests, objectives, standards, and sympathies creating a psychological sense of unity of groups or classes. Referring to the ties in a society that bind people together as one; it is also a significant concept in all major religions, which is closely related to the golden rule - of treating others like one would like to be treated oneself. It has found entry in the Charter of Fundamental Rights of the European Union and is mentioned in the Universal Declaration on Bioethics and Human Rights.

Organic solidarity comes from the interdependence that arises from specialization of work and the complementarities between people-a development which occurs in "modern" and "industrial" societies (Thijssen, 2012). The connection between the social and the biological aspects in the concept of solidarity was expressed by Peter Kropotkin. According to him, mutual aid, or cooperation, within a species has been an important factor in the evolution of social institutions. Solidarity is essential for mutual aid; supportive activity towards other people does not result from the expectation of reward, but rather from instinctive feelings of solidarity (Kropotkin, 1908/reprint 1998).

${ }^{4} \mathrm{C}$-suite refers to the executive-level managers within a company. Common c-suite executives include chief executive officer (CEO), chief financial officer (CFO), chief operating officer (COO), and chiefinformation officer (CIO). Retrieved from Investopia October 2020.
} 
The worst consequences deriving from COVID-19 are not due to the Virus itself. Besides the pain of illness, unemployment, loss of loved ones, and death, there is also the grief of waking up to realize that the system that we have evolved in is unable to cope with this Pandemic. What is happening now was predictable (and has been predicted by experts for years). This rude wake-up call is a prelude to the experience that many of us will undergo one day, when we realize that we have lived a life of complacency; busy yet empty; filled with action yet lacking aspirations; abundant in things yet void of meaning.

For many of us life over the past decades was a tide of trials, which we observed from the passenger seat. The Society that we are part of was shaped by others. Following the way of least resistance, we adopted a bystander perspective. ${ }^{5}$ We stepped sub-consciously in an attitude of either willful blindness, by shutting out the evidence of suffering around us and in other parts of the world; or we saw and felt the misery yet resigned ourselves to helplessness. Witnessing injustice and deprivation, indifference and inability we felt impotent. Relegated to being silent passenger on a giant truck that thundered down the highway we shut out our soul when it cried for meaning. We quieted our heart when it hurt with injustice - against ourselves or against others. We disregarded our mind when it questioned the status quo, and we used our body to enjoy what was at reach, numbing the uneasiness inside with pleasurable purpose placebos from the outside. From money-making to social media surfing, from savory foods over fitness to fun with friends; our body was an interface to cope with the quest for meaning by quietening it. Until this physical interface of ours became the collective battlefield that reminded us how fragile our apparent superiority is. Physical safety is a fundamental human need. Disease thus arouses our most basic instincts; it activates the animal instinct of fright and flight. Pushing individuals to invest all available resources in the preservation of themselves and their close kin. In parallel, however, remains the undercurrent of intuitive relations within a wider realm of interpersonal connection; and the pursuit of self-transcendence (Maslow, 1996). Humans are different from animals and even under stress they have the power of choice. Choosing how we react to a situation is our ultimate asset, the one distinctive feature of human dignity that must be preserved and nurtured under any circumstance (Frankl, 1946), including in the current context.

Today's challenge is not the Virus.

It is the system in which we operate, which caters to few at the expense of many. A system that we created, constitute and maintain. The national response and rehabilitation plans that are underway around the World to fix COVID-19 will not fix the problems that predate the Pandemic. If we do not make a couple of conscious choices to change our course of action, individually and collectively, we will get more of the same. Eventually we will fall back into the trap of past behaviors, the ways of thinking and feeling, of experiencing and expressing ourselves that we had

\footnotetext{
5 The 'bystander effect' refers to a behavior pattern whereby individuals are less likely to help someone in need when other people are present; the greater the number of bystanders, the less likely it is that one of them will help (Darley \& Latané, 1968). Several factors contribute to bystander apathy, including ambiguity of the situation, group cohesiveness among those who observe, and diffusion of responsibility that reinforces mutual denial of a situation's severity.
} 
been used to before the COVID-choc. If we do not endeavor individual mind shifts our collective mindset remains cast in stone, as do the habits that derive from it (Kahnemann, 2007). When self-centeredness and indifference are condoned by the majority, people whose survival depends on compassion and solidarity are shut out. Those who are outdoors are often not at fault, because they never had a chance to enter the room. We can change that. The central message of this article is that society can and must be reverse engineered to finally establish a context where individuals are lifted to fulfill their inherent potential. COVID-19 offers an opportunity to do that because it uprooted the status quo; but this momentum will not last much longer.

Each of us has a unique opportunity to bring change by being change. Independently of COVID-19 our personal life situation endows every individual with a unique combination of resources, from which springs the unique opportunity of contributing to solve the challenges at stake; nobody can seize this opportunity in exactly our way. This set-up engenders an obligation to translate privilege into practice (Walther, 2014). Once this dynamic is acknowledged and addressed by a critical mass of people, the prevailing social climate shifts. A new social norm arises (Bicchieri, 2016). The neuralgic point herein is to get started and inspire others to follow. Because being social animals, we want to fit in, or at least not stick out. The more people follow a certain trend, the more likely we are to follow that track (Biccheri \& Xiao, 2008). The central question of the present pages revolves around our ability to systematically nurture a blissful dynamic. Instead of zooming in on the animal urge of self-interest, we can choose to zoom out to the other evolutionary trait that has helped humankind to not only survive but thrive in the face of adversity: Solidarity (Nowak, 2011). Shifting from self-centered behavior patterns to a pro-social attitude may be an effort at first; but it becomes easier and more pleasant as time goes by. Even activities that feel unfamiliar and uncomfortable at first gradually become natural habits due to changes in the synaptic connections in our brain. (Doidge, 2011). Our physiological set-up can thus be a curse or a blessing when it comes to habits that are conducive to social change. Neuroimaging has shown that after a person has performed an action once, subsequently even observing other people perform it strengthens the related mental hardware, the neurological liaison in the brain. Even just thinking about engaging in the action again may nurture the initiated neural pathway (Doidge, 2015). The crucial aspect is that the circuit begins only with action by individuals themselves. Solidarity is not an empty word; it is performed by people who choose to engage in it. Change, both small and large scale, starts from the inside out - with the decision of one individual to reverse course. It is nurtured from the outside in through the manifestation of that decision as action (Ibarra, 2015).

This process entails a simple 4-step sequence: Individual set-up $>$ Personal aspiration $>$ Distinct responsibility $>$ Collective transformation. Eventually a new normality sets in, only that this time self-centeredness and indifference have been replaced by compassion and solidarity.

Eventually the Pandemic will leave the stage and our life will settle again. The question is if society will continue to play the same game the same way-with slightly reshuffled cards, but the same players around the table and guided by the 
same rules. Solving the COVID-19 conundrum is not about bad or good actions; it requires a different take on the parameters at stake. We are at a crossroads.

Beyond its moral underpinnings (Haidt, 2006) our obligation to protect and promote the equal enjoyment of all rights for all people has been legally enshrined. (Universal Declaration of Human Rights (UDHR), 1948); this includes the right to health (Office of the United Nations High Commissioner for Human Rights (OHCHR) and World Health Organization (WHO), 2000). And yet, inequity has been developing on and under the radar for centuries. Today, it is obvious that many have little, and the special few have a lot. Despite the efforts of many people around the World to make change happen, many others did not join them. Furthermore, the aid system that has been devised to alleviate suffering is unable to cope with the increasing load. Created to help both those who are affected by acute emergencies, usually triggered by natural (e.g. cyclone) and human made (e.g. war) disaster, as well as chronic issues such as poverty, the 'aid sector' can not close the gap that separates billions of people from the enjoyment of their most basic rights. This situation is not sustainable. Because ultimately, we are not alone in the game of life. Playing to win requires a cooperative scope.

The beauty of personal effort for collective interest derives from the related multitude of benefits. Acting for and with others has direct and indirect consequences. It is a win-win-win-win. Individuals who allocate resources, be they in the form of money, assets, power, or social connections, can contribute to a change of the circumstances which they may bemoan as unsustainable. They shift from bystander to player. Such a mindset of agency and solution thinking nurtures their selfunderstanding (Peal, 1952) and adds the dimension of a larger purpose to their life (Frankl, 1946) [Win-1]. This strengthens their physiological and emotional wellbeing (Gordon, 2009) [Win-2], whilst improving the overall societal environment they evolve in [Win-3]. The latter is felt positively at all levels of society, offering mental and physiological, social and economic benefits (Wilkinson \& Picket, 2009) [Win4]. Compassion, feeling with others paired with the desire to relieve that suffering, is here not explored as a philosophical concept, but in view of its practical contribution to the solution that must be found. "Compassion is a question of human survival" (Lama, 1990). Solidarity manifests the combination of compassion (heart) with an understanding of the context (mind) and the aspiration of purpose (soul). When we combine the understanding of our own possibilities (mind), with the caring for (heart) and connection with others and manifest the result as tangible action for others (body) we move towards completion (soul). The Golden Rule ("do to other as you want done to yourself”) is universally recognized. In the COVID-19 context, practicing it embodies the convergence of religion and science, of principles and praxis.

We need to change how we perceive ourselves and our environment.

"Everyone has the right to life, liberty and security of person." (The Universal Declaration of Human Rights (UDHR) 1948, Article 1). Freedom and safety are among the many features of life that many of us who live in highor medium income countries have taken for granted; from social services to abundant commodities to autonomy of movement. The situation that has set in since COVID-19 is a reminder that neither of these is acquired once and for 
ever. The Pandemic sadly exemplified that "the management of social issues is subject to historical contingency and strategic re-articulation. And thus, the risk of regress." (Minujin \& Grondona, 2013). This relative validity seems no longer limited to traditionally trampled rights such as freedom of speech (UDHR Art.19) or of political association (UDHR Art.20), but increasingly embraces rights once thought as absolute. In the present context the right to health includes for many vaccination and access to intensive care. Both are limited - and these limitations should neither be defined by geography, nor nationality or financial means.

Individual and collective wellbeing require an attitude of purpose that is not directed towards personal benefit but collective completion. The POZE paradigm that these pages are based upon, is anchored in the understanding that human existence is the result of 4 dimensions which stand in equal proportion to the 4 collective dimensions of society. Wellbeing requires a synchronization of these twice 4 dimensions, within and between each other. We need to shift from an attitude of self-centeredness to an all-embracing vision of life and living. 'Happiness' requires purpose; and purpose reaches beyond the self. Individual and collective change in attitude and action is needed to build a future that is worth living for people and populations alike. (Seligman, 2011). The word POZE has different meanings, it: i) represents the 4 outcomes of the logic that underpins it (Perspective, Optimization, Zenith, Exposure); ii) is an acronym that encompasses the 4 core concepts of the paradigm (Purpose, Om, Zoom, Expression); iii) translates as 'inner peace' from Haitian Creole, country where the dynamic began in 2017; and iv) illustrates an exercise to nurture inner peace daily (Pause, Observe, Zoom in, Experience) (Walther, 2020a). Furthermore, it stands for is the description of a movement: People On Zenith Exploration and reflects the layers of social optimization in covering Purpose orientation that transcends personal interest, Optimism for the future; Zeal to achieve the best outcomes for humanity; and Exploration of opportunities with the ambition to move beyond forgone conclusions. These relate to the overall aim of optimization yet go deeper by establishing a more granular mental matrix.

A practical outcome of POZE is the role it can play in helping individuals identify their purpose in this life, as a steppingstone towards sharing their own best self with others and hereby contribute to make the World brighter. It is based on the understanding that individual wellbeing is the cause and consequence of collective welfare. One without the other is unsustainable. (Walther, 2020a, b).

The Pandemic does not replace the old problems with new ones. The latter come on top. Climate change, inter-and intra-national inequities and inequalities, unsustainable consumption and production patterns, dysfunctional private business practices and international aid structures, individual deprivation, as well as solitude and lack of purpose are still wanting solutions. One cannot improve the past, but it would 
be stupid to not project ourselves into a better future by taking proactive steps in the present to reach it. Steps of change entail a shift of attitudes (mind), from judgement to compassion; and actions (matter), from bystander to driver. The post-pandemic world offers an opening to rebalance society; and overcome the poverty of meaning, the material and mental deprivation that has colored the life of too many individuals for too long. Poverty is an imbalance of needs and means. COVID-19 opened a door to move forward and even out of that imbalance, to shift consciously from selective exclusion to inclusive balance. Filling the gap is in the interest of everyone; even if it involves short-term discomfort for those whose pile shrinks. Ultimately everyone is better off in a society that is marked by equity (Wilkinson \& Pickett, 2009).

We do now have a vast panoply of technological tools at our disposition. ${ }^{6}$ We are better connected and (potentially) better coordinated than ever before in history. And the physical and nutritional status of most people is much better than a century ago.

We know more, have more, and can do more than ever before. The 7.8-billiondollar question is whether we will use this to serve everyone and hereby our own respective good. Are we ready 1) to acknowledge that each of us is driven by two opposing instincts - one being the inclination of inertia and self-interest (Thaler \& Sunstein, 2009); the other to cooperate with others and care for those who are in need (Nowak, 2011); and 2) to accept that we have the choice to overcome the former and nurture the latter in favor of pro-active connection and cooperation with others for others. Change is uncomfortable, and it feels even more cumbersome if we seem alone in our endeavor. We are willing to adopt new behavior patterns (including those that are uncomfortable) as a mean to fit in (Biccheri \& Xiao, 2008). The choice of one individual can thus plant the seeds of the dynamic that this 'new' behavior pattern follows.

COVID-19 is not the end of the World. It is merely the end of the world that we had grown used to. It is not astonishing that COVID-19 happened now. It is astounding that nothing similar happened earlier, and it would be stunning if we were not able to draw drastic intellectual, emotional, and aspirational conclusions and based on them to re-orient our individual and collective behavior. The next section introduces a set of common principles that will guide the subsequent reflection.

\section{Concepts}

This section introduces the principles and dimensions that underpin our individual and collective experiences.

Everything is connected, internally and externally. The multidisciplinary framework that is briefly described here provides a 360-degree perspective to look at the post-pandemic set-up. Individual behavior, institutional iterations, wider systemic dynamics, and their part in societal transformation are analyzed through a prism that

\footnotetext{
${ }^{6}$ For details on the way in which technology can be used as a catalyst of social change at scale see Walther (2021).
} 
highlights their interconnection. Emphasis is placed on the core of these interplays: individual choices, and the responsibility to make these choices with awareness of the social context in which they take place. As governments around the world struggle to cope with the fall-out of COVID-19, the empowerment of their citizens is more important than ever.

4 principles shape life, influencing the dynamics within each dimension and the interplay in between:

- Change - everything is constantly evolving. People and places, circumstances and considerations vary depending on the context in which they take place.

- Connection - everything is linked to something else that influences it and is influenced by it. As illustrated by the corona virus, nobody lives in a bubble. The attitude and action of one person can have wide-reaching consequences on their community and wider society.

- Continuum - everything is part of whole. We are part of something, a community, a country, Planet Earth. Whether it is a state, an approach or an outcome - it must be perceived and planned as part of a puzzle with many pieces.

- Complementarity-everything is completed by the presence of something else (which could be its opposite).

These principles are universal. They apply to everyone everywhere; mutually influencing each other through time and space. The causes and consequences of these principles are the 4 dimensions that shape our individual being and the 4 dimensions that shape our collective experiences. Change starts from the inside out, and is nurtured from the outside in. Thus two mutually reinforcing undercurrents operate in both arenas:

- From the center to the periphery: Everything begins inside, with the continuous interplay of 4 dimensions that shape every human being: soul, heart, mind and body; expressed as aspirations, emotions, thoughts, and behavior. What we aspire to influences how we feel and think, which ultimately influences how we act. Similarly, from individuals flows the impulse to create or modify communities and institutions which influence the course of countries that are part of supranational dynamics. This twice 4-dimensional kaleidoscope, together with nature, forms the Planet. Following an Inside-Out dynamic the utopian sounding statement 'we can change the world' becomes a concrete pragmatic undertaking. Starting at the core of the center - the aspiration of individuals for meaning, and the action that derives from it influence the collective course (Fig. 1).

- From the periphery to the core: Nothing happens in a vacuum. The evolution of micro, meso, macro and meta; manifested as individuals, communities, countries, and Planet Earth depend on each other. Global evolutions such as climate change impact the national context and the communities that exist in it, which affects individuals who constitute it. Every individual mirrors this Outside-In dynamic - physical experiences influence our thoughts and 
feelings in a situation which leaves an imprint in our memory for the future; while affecting how we (re) act in the present situation. Simply said - what we do influences our environment, and thereby our experiences. Thus, our action impacts what we think and feel now, which impacts our decisions in the present, and our decisions in the future. This has consequences on our aspirations.

Everything is linked, from the inside out and from the outside in. Our body is the interface between the inner and outer realm. Our thoughts are thus the result of an intricate mixture of genetic disposition, education, beliefs, memories, upbringing and environment. They influence our emotions and aspirations, our physical experiences and expressions; and are influenced by them in return (Kahnemann, 2007). How we feel, think and as a consequence behave today is not only influenced by who we are presently; it is influenced by our past being; and, it influences how we will feel, think and act tomorrow. Change can be induced at any moment, if we choose it; leaving physical traces in our mental hardware which will help that change become durable over time; at the individual level (Doidge, 2011); and through the attitude and action of the 'changed' person, at the collective level.

Fig. 1 From Aspirations to Sensations. Everything is connected, from the inside out and from the outside in. Our aspirations impact our emotions, which influence our thoughts and hereby our experiences and expressions (sensation). Conversely, the way in which we express ourselves causes certain experiences, which result in physical sensations that trigger thoughts and emotions, which fuel or alter our aspirations; and shape our memories. These memories influence our emotions and thoughts in future situations, and hereby our future expressions and experiences

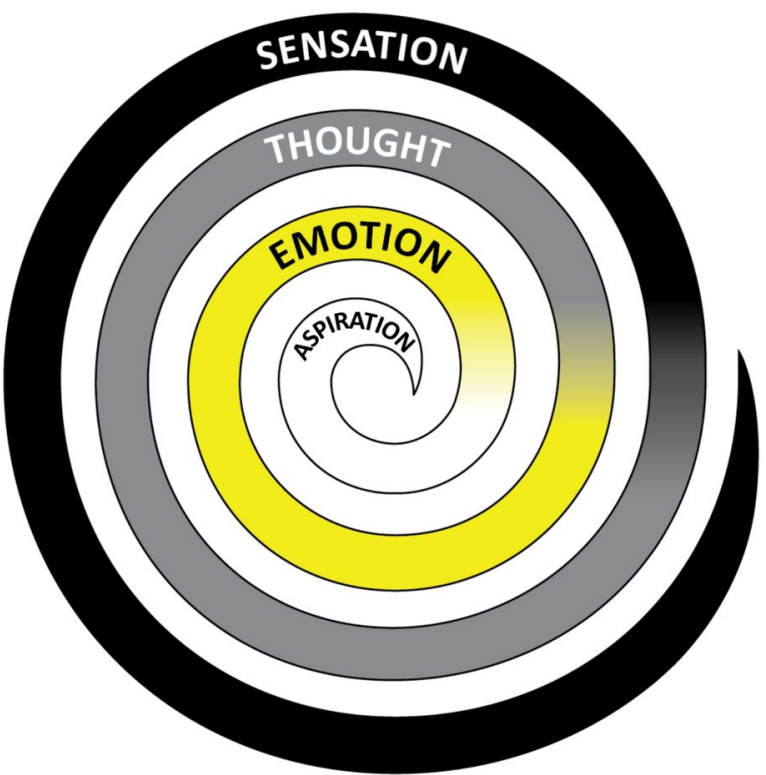


Representing the multidimensional micro dimension of a collective multidimensional system, individuals express and experience the meso dimension via the communities they are part of; voluntarily or biologically, directly or indirectly. The contours of economic, political, cultural systems form the macro level not as a given but as a result of human decisions and behavior (Gräbner \& Ghorbani, 2019). Micro, meso and macro dimensions operate within a meta dimension that is the interface between humankind and nature, between the tangible and the unknown. Within a seamless continuum one dimension is influenced by the others and influences it in return (Fig. 2).

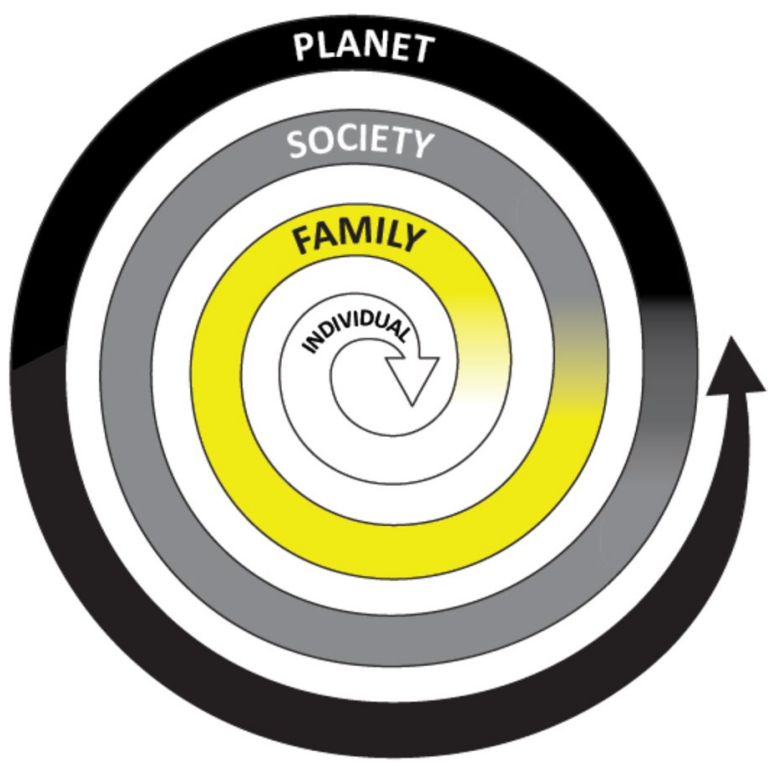

Fig. 2 From individuals to Planet. Everything is connected, from the inside out and from the outside in. The individual is the smallest component of a global system, and part of various communities, which result from biological, social or professional constellations. Individuals and families/communities form society, within the contours of nation states, economies, cultures. These three dimensions are part of Planet Earth, coexisting with nature. Whatever occurs in one dimension has consequences on the others. Individuals influence the communities they part of, and hereby society, and the planet. Whereas changes in the environment impact the dynamics of society and the communities and individuals that it is made of 
Understanding how we function is necessary to understand ourselves, and gradually master this 'How'. Being aware of the relationship between mind and matter, inside and outside is the first step for individuals who want to shift from being the result of semi-automatic processes, to agency and ownership of their own actions. Such individual changes impact, through various channels, other individuals as well as organizations and institutions and, eventually, national and international policies.

\section{Perspectives}

This section looks at the implications of inequity which has come to the forefront during the pandemic. We then turn to the P-Puzzle as a tool to analyze institutions, seeing their central role as building blocks of an equitable society.

Millions of people around the World are affected both by the Virus and the measures taken to contain it. Individually and collectively we struggle to grasp the situation, deprived of reference points. We are left without framework nor baseline. Being in such mental no-man's land sets us free to evolve in two alternative directions: Either we progress towards a society where a person does not just count as a statistic, but cares about others and is cared for by them. Or we regress, lingering within a sterile state of mind and matter that appears like a return to 'normality', and keeps on nurturing the groundswell of distrust that began to set in before COVID-19; until the bubble bursts.

COVID-19 has put the systems that we took for granted on the spot. The prevailing status quo is a systemic social paradox because the expanding darkness is not due to the Virus in itself. It is rooted deeper, in the systemic divide that is mainstreamed and condoned in 'our' societies. It has been cultivated unconsciously over centuries. "Rather than justice for all, we are evolving into a system of justice for those who can afford it." (Stiglitz, 2012).

In the best-case scenario the Pandemic may turn into a social equalizer by reminding us that we are all the same inside. Living beings with needs and desires. We aspire to meaning; want to feel safe and welcome; think about justice and wake up every day with the physical needs to eat, drink, sleep, love and learn realized (Maslow, 1943).

Simultaneously the past months made it blatantly obvious that we are very different outside; beings whose needs and desires are not equally addressed. Inequity is a disease that is worse than the Virus, because it cannot be halted by vaccines and masks.

The Pandemic is putting individuals and institutions, health and economic systems around the world under strain. The cracks that made us look into the social abyss, separate people within countries, and countries from each other.

\section{Inequitable Inequality Implications}

What has turned out to be a massive challenge for high income countries such as Germany and the US, is devastating for low-income nations. Already marred by 
structural weaknesses and insufficient social services before a major external shock occurred, most of their populations lacked social protection and enough savings. COVID-19 compounded chronic poverty with acute deprivation, due to the loss of income during social lockdowns, and the need for governments to reroute parts of their resources to respond to the virus.

COVID-19 figures that are broken down by race remain difficult to come by due to political resistance; however, the available statistics are disturbing. In many majority-white countries people from other ethnic and racial groups have less access to economic resources; an economic vulnerability which often translates to poorer health outcomes (Ro, 2020). Major discrepancies, in terms of both infection and fatality rates, are being registered in all countries where being in a racial minority is mirrored by economic hardship; like the US, South Africa, Australia and Ecuador. The figures do not illustrate that certain genetic circumstances make one race more vulnerable than another to contract the disease and/or to die from it; rather they offer a dire socio-economic x-ray of our Society.

Leaving aside access to quality care and testing, exposure itself to the Virus is affected by the economic inequities deriving from race, ethnicity and gender, due to the profiles of certain jobs. Around the world, certain groups are disproportionately represented in at-risk professions; such as transport, fast food, cleaning and deliveries; because of overcrowded habitations with poor hygiene; and due to the need of continued work during lockdowns. Furthermore, being substantially more likely to be unemployed or precariously employed, people from certain groups often face healthcare disparities; because they have no health insurance and are not able to afford the costs involved with doctors, medications and hospitalizations. Immigrant workers are less likely to protest unsafe working conditions; and to seek medical attention as needed. Overcrowding, in high- and low-income countries alike, access to hygienic bathrooms and handwashing facilities are additional factors that put some at higher risk than others.

The outcomes of containment measures and lockdowns are disproportionally harmful to informal workers without a safety net. They are the first to be laid off, and the last to find sustainable alternatives. Those who do not have a job that can be done remotely, have no wealth to fall back on, and if they live in a country without solid and sustainable social protection measures, they find themselves in the dark. But the racial trenches go deeper, down to racial biases phobias (Ro, 2020).

Without expanding the disturbing list of inequity further, one central point must be clear: Inequality is a matter of fact, inequity can be prevented. (Stewart, 2013). Inequality may refer to a simple imbalance; whereas Inequity refers to injustice. Income inequality results in large parts from inequity in society "Inequity will not be brought down by paying more lip service to it or by conducting more research that stays in an ivory tower. Only if we come to understand that inequity engenders near universal harm will we muster the courage to address it. "(Vandemoortele, 2019). The tangible feasibility of social change underpins the necessity of a change in mindsets. We are the same inside, and this sameness must be brought to the surface as a binding link that joins Society as it emerges from this crisis. 
Thus, at the same time as the sensation of crises engulfs us, an opportunity parades through the room. Never before experienced so many people around the World such a drastic experience that was the same at the same time. While for many this resulted in even heavier workloads and tighter timetables, for others the lockdowns resulted in a lot of freed-up-time. The latter is an occasion to contemplate, digest and react to the unfolding situation in a way that is not determined solely by the instinctive impulses that shape our behavior in times of rushed routines.

Translating the opportunity of this crisis from potential to practice, requires a multitude of individuals and institutions. We have looked at the individual factor, covering aspiration and action under the angle of the personal responsibility to choose action ("Contextualizing a Post-Pandemic World" section). This is now followed by an overview of the institutional space. Awareness of the dynamics that underpin who are and what we do becomes acutely relevant in the context of institutions - the meso dimension, because they amplify and nurture individual dynamics. This matters in particular when it comes to institutions that were established to help people in need; and even more so, in the case of supranational organizations whose scope and impact is global, such as the United Nations (UN).

For lack of space the following will concentrate on institutions that are meant to make the world better. Because they must live up to the expectations that derive from their mandate. To make this happen the 4 components of their set-up must be acknowledged and synchronized. It should however be noted that the P-Puzzle applies to any institution.

\section{The P-Puzzle. A Fresh Perspective on Institutions}

The need (and absence) of international collaboration was put front and center in 2020; and exacerbated with the competition over vaccins in 2021. To compensate for the consequences of the Pandemic at local and national level global solidarity is required. This entails coherent action by institutions, including supranational organizations such as the UN. The P-Puzzle applies the POZE paradigm to organizations to distil the components that matter for a change of international and externalized dynamics (priorities, people, positions, programs). Before we analyze the P-Puzzle, we explore the classic definition of these entities that make up the meso-dimension; serving as an intermediary between individuals and macro-dimensions, be it country, culture or economy.

The term "institution" commonly applies to both informal institutions such as customs, or behavior patterns important to a society, and to certain formal institutions created as entities or organizations. The five basic social institutions are the family, government, economy, education and religion. (Hodgson, 2006). In the context of this article the term institution refers to this definition as an entity. Institutions embrace at least two micro-entities (individuals) who behave and interact regularly and with common purpose. I.e. a dialogue among strangers in a bus does not constitute an institution - even if they follow certain established rules of behavior or politeness.

Institutions are integrated systems of rules that structure social interactions in particular ways (Hodgson, 2006; Knight, 1992). Throughout history, they 
have been devised by human beings to create order and reduce uncertainty. Together with the standard constraints of living in a community they define the choice set that individuals have at their disposition; which impacts the opportunities, risks, and difficulties and hence the prospects for (tangible or intangible) rewards and, thus, the feasibility of engaging in certain interactions. They evolve incrementally, connecting the past with the present and the future (North, 1991).

Institutions, conceptualized as entities, are determined by their internal why (priorities), who (people), whereto (positions) and what (programs). When we look at them, a distinction between, on the one hand, the nature of the institution (as an internal set-up which determines its organized identity), and on the other hand, the scope of its action (which justifies its existence based on external delivery) emerges. Both influence the prevailing organizational culture.

Often bemoaned as the impediment to institutional efficiency and individual morale, organizational culture is the organically evolving derivative of individual and collective behavior. This is the chicken \& egg trap; because who was there first? The individual who is influenced by the prevailing culture, or the culture that derives from individual and collective behavior within the organization in which these people evolve? Sustainable Culture change starts from the inside out, with the attitudes and actions that underpin the observed organizational culture, i.e. the aspirations of individual staff (Walther, 2020b). The quest for a Why, the aspiration of purpose pursuit, connects people and the places they work at. Institutional culture is the organic manifestation that derives from the meaning and manifestion that this Why takes. It connects individuals and their institution, and materializes in the best case scenario as commitment to a collective cause. Placing the cursor on only one side of this equation, be it organisational restructuring or change among staff, means to answer only half of the questions at stake. To understand the whole, one must look at the parts that constitute it (Singh, 2018). A holistic perspective is required for change that matters and lasts. The P-Puzzle applies the multidimensional POZE prism to institutions, to understand and optimize how individuals and institutions influence and shape each other.

\section{The P-Puzzle: Laying the Foundation for Institutional Change, and Global Solidarity}

When it comes to institutional change multiple agendas are at play; and the highest hurdles to overcome may be neither budget constraints, deadlines or external expectations, but resistance by people inside the organization. Not only those who are thriving under the existing rules; but also, those who cling to the known void for fear of uncertainty. Functioning like social contracts that specify the rules of membership, organizational cultures are unwritten yet sacred to many (Pisano, 2019). The P-Puzzle seeks to unpack the foundations of these rules.

Equaled to the 4 dimensions of the human being we look in a nutshell at (i) the institutional Priorities that relate to the aspirations of individuals. 
Encompassed by the mission statement it is the organization's Soul; (ii) the People working in the institution who correlate with human emotions. Staff represent the pounding Heart that gives life to organisms; bureaucracies and bodies alike; (iii) Positions which correspond to the human Mind. Rules and regulations bring rationality to connect aspirations and action (at least it should); and (iv) Programs activate the outer space, the 'body' for they resemble our external behavior, by manifesting individual/institutional intentions. They translate the Priorities that have been thought out by People in line with the prevailing Positions. The following paragraphs summarize certain challenges that mark institutions, within the global ambition of social change; these parameters impact their efficiency, and power ${ }^{7}$ :

Priorities Why are we here? Institutions such as some United Nations (UN) agencies and programs are precious assets, and critical players, in the collective aspiration to build a happier and more inclusive World where human rights are upheld. From humanitarian issues (conflict, natural disaster, epidemics etc.) to lingering development questions (such as the lacking quality of education, health care, nutrition, water, sanitation, and housing) much was at stake already before the Pandemic hit the globe.

The list of priorities keeps on expanding as Society continues to evolve. In 2015 the 17 Sustainable Development Goals (SDG) were launched to overcome the barriers that prevent a majority of the 7.8 billion people on this Planet from living up to their potential (Sustainable Development Goals web 2020). Set to achieve their objectives by 2030, they succeeded the Millennium Development Goals (MDG) which had tried for the preceding decade and a half, and failed, to rally the Worlds' resources and attention, to address these barriers. Despite billions of investments these issues have been lingering for centuries. (Vandemoortele, 2018).

People Who is acting for whom? Staff are the living cells of an institution. They are the heart that brings it not only to life but enables it to thrive. Diversity of staff is essential because it allows teams to look at issues from different angles. COVID19 has brought to light the diverse mindsets that co-exist in many organizations and styles of work.

On the one hand there are technical experts who are used to work on administrative issues, policy design and program analysis; on the other hand, there are emergency experts who are familiar with the design, implementation and monitoring of immediate, short-term responses. Whereas the former group of staff is used to slow onsets and systemic modifications that operate over a longer-term

\footnotetext{
7 As explained by French and Raven (1959) who identified five basic sources of managerial power: (1) legitimate (formal or bureaucratic power); (2) reward power; (3) coercive power; (4) expert power; and (5) referent power. The first three power bases follow from a formal charter of authority; the last two depend upon the competence and qualities of the individual (where influence is primordial).
} 
period; the latter is most familiar with quick shifts and ad hoc shocks. Bringing out the strength and complementarities is required for optimum efficiency and creative results.

Positions Where do we situate ourselves? Positions relate to the rational setting of the institution. It is the intellectual framing that determines its shortand medium-term orientation. Entailing procedures, rules and regulations, job descriptions and standard operating procedures, this component of the institutional organism is at the same time woven through everything and nowhere centerstage. It may be overlooked completely or become the focus of attention that occupies the mental real estate of people who joined to uncover solutions for pressing social issues.

Bureaucracy is the mothership of positions. It is what comes quickly to mind when staff are asked about the impediments to their work. As for many complaints in this context this reverses the table - because who created whom? Positions are set to standardize and facilitate an institution's functioning. They are designed by people for people. If they turn into impairments, the wrong turn was taken. The question then is not to complain about bureaucracy as a given that is immutable, but to trace back the steps that have led to the status quo; and more importantly to focus on changing it. If the latter prevents the institution from translating its priorities into programs such candid examination is urgent.

Programs What are we doing externally? Solid relationships with public authorities and local organizations are essential for institutions that ambition to offer programs for the benefit of people who are deprived of the enjoyment of their basic rights. Individuals, from the so-called 'beneficiaries' over service providers to state officials usually know best what their needs are. ${ }^{8}$ Only if they get a chance to participate in the programs that are meant to 'help' them, ideally throughout the planning, implementation and monitoring stages, that program has a chance to succeed.

To yield impact that matters, programs must be tailored to address the immediate, medium and long-term perspectives of those who are supposed to benefit. Organisations dedicated to social change must perceive and position themselves as part of an organic continuum that links urgent life-saving assistance for individuals, with recovery and boost-up support for communities, passing via peace building for countries, while pursuing the genuine empowerment of people. All efforts must loop back to the fulfillment of individual human rights as the core of this collective effort.

\footnotetext{
${ }^{8}$ The term beneficiary commonly comes with a passive connotation, that is often negative. To be efficient and effective genuine participation and inclusion in the decision-making process is required (Easterly, 2007).
} 


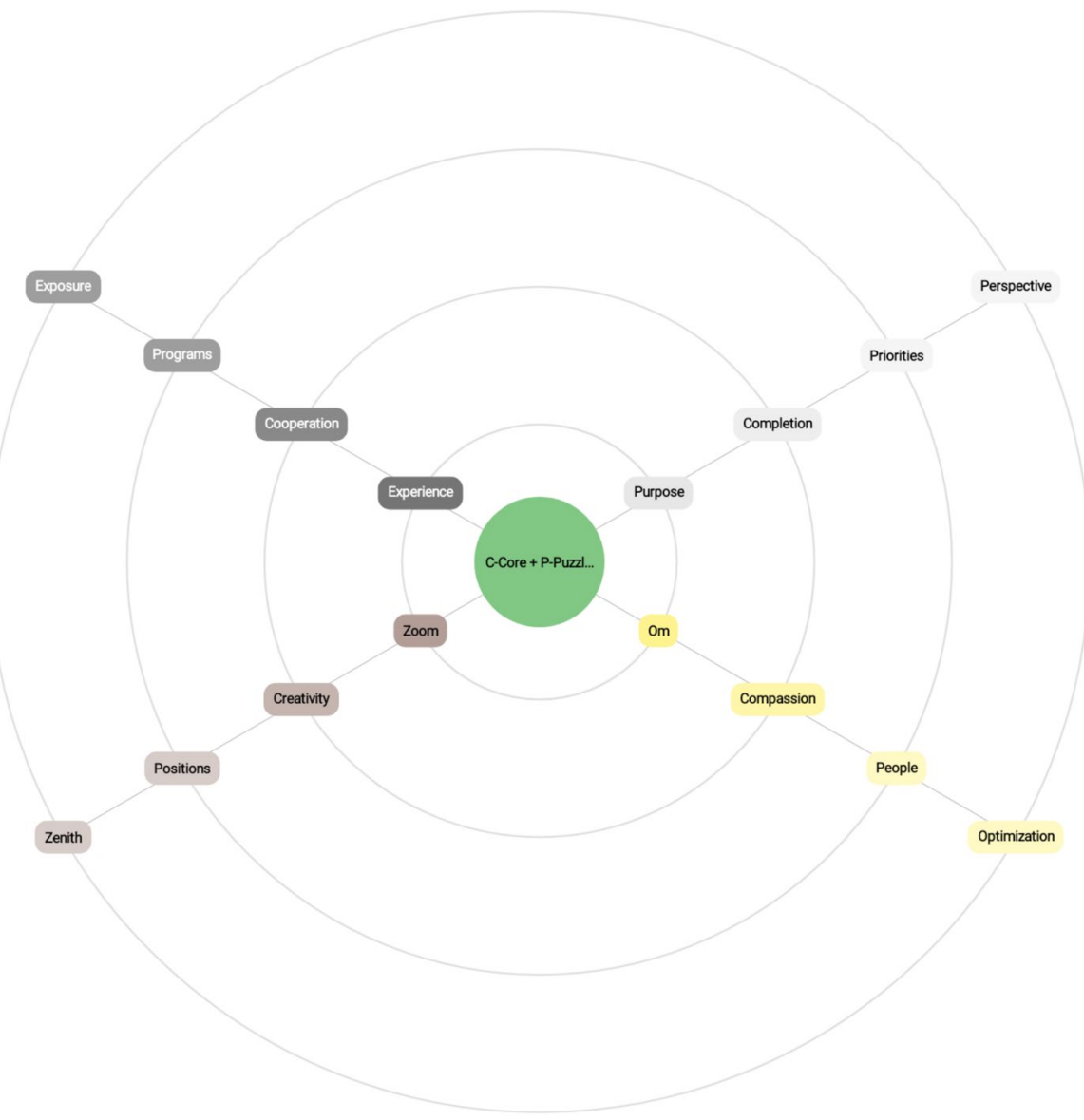

Fig. 3 C-Core + -P-Puzzle. Everything is connected, including the causes and consequences of our choices. The graph integrates (from the core to the periphery the objectives of POZE, with the $C$-Core attitudes; passing via the P-Puzzle to reach the Outcomes towards which POZE is geared: Purpose orientation leads to the gradual completion of our being, which should be a priority for individuals and institutions alike; such an orientation opens a new perspective on the status quo. Om is the universally recognized word for emotional unity, it serves compassion for us and others. It is the required streak of people for people that eventually leads to an optimization of social interactions. Zoom stands for focus (think of a camera rather than the all-pervasive communication platform) which leads to the bundling of ideas in a creative stream of solutions that strengthen the position of institutions in their setting. Moreover, and combined with the others, it gradually leads to the Zenith, the best version of the self, and hereby of society. Finally Experience of the presence (rather than a distracted half-mind) nurtures cooperation; being aware of our environment and the people in it is the first step to acknowledging and appreciating our mutual complementarity. In the context of institutions this leads to programs that are relevant and make the most of resources that each player brings in; provided the latter step out of their respective comfort zone, seeking Exposure to the unknown territory of radical change for the common good. Each component of the multidimensional organism depends on the others to unfold its potential. The same holds true for the potential of micro, meso, macro and meta dynamics whose direction depends on us via the choices we make 
We conclude with a set of recommendations that are framed by the perspective that arises when the C-Core is applied by individuals and the P-Puzzle used to optimize institutions. The post-Pandemic world requires change commitments that are pursued individually and collectively, within institutions and beyond (Fig. 3).

\section{Soliciting Solutions. A Way Forward}

This Section uses the C-Core (Completion, Compassion, Creativity, Cooperation), as a set of mind-shifts needed to set individuals and the society they operate in up for success. It concludes by putting the pieces of the play, C-Core and P-Puzzle together, within a holistic perspective to re-think the status quo.

When something is shattered to pieces it cannot be fixed. The scenario that emerged from 2020 is very different from the social setting that existed before the Pandemic. The confidence of many people into the systems they took for granted is gone. Thus, the question is neither to pick up the shards and patch them together in a makeshift something; nor to come up with much more of the same that failed before. The time has come for a new normal.

Shutting out the World while it spills out of control is one option to cope with the unfamiliar circumstances. The other option is to seize this chance to build a different tomorrow. We can use the rapidly shifting tectonic plates of our own life, of our community and country to design and deliver something that is radically different. If individuals change while the entities that they are part of remain engrained in their ways of doing; significant delays accompanied by much loss of life and livelihoods occur. Eventually, however, as the number of change-makers increases, the accumulation of their behavior triggers ever widening ripple effects at the meso, macro and meta dimensions; which then become impossible to ignore. Change may take time, but it happens - provided someone starts. Once we have begun, a new dynamic expands gradually throughout the 4 dimensions of our individual, and from there of collective existence. It takes time to move from the present void towards a tomorrow that seems worthwhile. Progress depends on circumstances and commitment. COVID-19 has placed the former in our lap, the latter is our hands. Damaged systems do not heal overnight. But once the first individual changes, others follow; and with them the circle expands; until a critical mass of people is reached, and the social tide turns. Eventually a new social norm arises which is characterized by compassion and solidarity. We conclude with the $C$-Core to summarize a mindset that can accelerate that tidal turnaround.

\section{The C-Core}

When our values, aspirations, thoughts, words, and behavior are aligned and coherent, then we are at peace, inside and with others. Conversely, if our external expressions and our personal values, aspirations, emotions, and thoughts are out of synch and misaligned, then 
our being is fragmented. This misalignment is mirrored by incoherence in our expressions (words, actions); which affects our relationship with others, and hereby our experiences. ${ }^{9}$

The $C$-Core is a way to come to terms with the new status quo. It proposes the seeds for a Society that is marked by Completion - the aspiration of individuals to move forward and up to gradually realize their inherent potential; finding their own completion in complementarity with others, Compassion - the feeling and respecting of our own suffering and that of others; Creativity - the mindset of looking for solutions that lie in unknown territory, beyond our respective comfort zones; and Cooperation - the physical readiness to seek complementarity of skills and assets.

When we combine the twice 4-dimensional logic that was introduced at the beginning ("Contextualizing a Post-Pandemic World" section) with the 4 components of the $C$-Core operating at full speed, the best-case scenario will set in gradually. Starting from the micro-level expanding gradually throughout the 4 dimensions of our collective existence:

1. If individuals around the World acknowledge, accept and address their instinctive need for purpose and connect with others based on meaning, their self-perception changes; this impacts their behavior (micro).

2. When institutions and communities (families, organizations, corporations, universities, schools, political parties, associations, etc.) dispose of a critical mass of people who behave in line with the above, then the priorities, positions and programs of these entities change (meso).

3. Individuals and institutions/communities are the building blocks of economies/countries. When they change, the systems which they are part of change (macro).

4. When micro, meso, and macro dimensions are aligned with the understanding of systemic solidarity and shared purpose, then humanity gradually moves towards a rebalanced relationship with the environment that it is part of (meta).

Institutions and systems are like large ships that take a while to turn around. If individuals change while the entities that they are part of remain engrained in their ways of doing, then tangible change is (or seems) stalled. Eventually, however, as the number of change-makers increases, the accumulation of their behavior triggers ever widening ripple effects at the meso, macro, and meta dimensions; which then become impossible to ignore. But once the first individual changes, others follow. Every changed person makes a difference by amplifying the dynamic underway.

\footnotetext{
${ }^{9}$ Human beings strive for internal psychological consistency to function in the world. A person who experiences internal inconsistency tends to become psychologically uncomfortable and is motivated to reduce what is called 'cognitive dissonance'. They tend to make changes to justify the stressful behavior, either by adding new parts to the cognition causing the psychological dissonance or by avoiding circumstances and contradictory information likely to increase the magnitude of the cognitive dissonance (Festinger, 1957).
} 
Potential scenarios (Numbers correspond to the cells in Fig. 4).

Looking at the 4 dimensions of our being we notice the impact that their mutual interplay has on our personal wellbeing, and on that of others. Starting from the place that individuals occupy in the meso, macro, and meta dimensions which they are part of, 4 societal settings could can arise out of this crisis (and any other largescale catastrophe):

1. In the worst-case scenario, we end up as a fragmented collection of indifferent people, who do not realize the suffering of others and do not care much about anyone but themselves (fragmentation \& indifference) - this is the stylized preCOVID-19 status quo.

2. Next comes the scenario whereby we exist in our respective bubbles; limiting our energy and attention-span to our own interests and circle of acquaintances. Lack of trust and shared purpose separates us from each other and the environment we evolve in. However, thanks to internet and media we are not only acutely aware of the suffering of others, but of our own potential to do something about it (fragmentation \& consciousness) - this is unstable. As illustrated during COVID-19, restricting our attention to our personal preoccupations extrapolates an individual's risk of falling prey to collective external hazards. In a way, this stage is worse than the previous one because being aware that their personal values and their behavior are misaligned people's psychological wellbeing is frayed.

3. Third stands the scenario in which technology connects us with others and the world 24/7. We know about the needs of others and are aware of our own potential of doing something to address them. We may have made various attempts to get involved, yet, frustrated with empty talk and political promises we have become indifferent to the circumstances around us. We have material resources at our disposition to do something about the issues that afflict society, but we cannot care enough to get up and act (connection \& indifference) - this is unstable, as either the indifference will lead to annul the connection or the connection will wake us up to care.

4. The final stage is (or could be) a new normality where we are not only aware of the needs of others but connected. Joined to one another by a shared quest for purpose we actively strive to address these requirements. We are so much in tune with ourselves and with each other that addressing the needs of others comes as intuitively to us as does action to satisfy our personal needs. With the alignment of our aspirations, emotions, thoughts, and behavior, doing for others what we hope for ourselves is no longer a conscious effort, but a regular expression of our individual humanity (connection \& consciousness). ${ }^{10}$

\footnotetext{
10 In game theory (e.g. Prisoner's Dilemma), the Nash equilibrium refers to a situation in which nobody has any incentives to unilaterally change what they are doing but, if cooperation where possible, a situation with better outcomes for everybody would ensue. The table in the text is similar to such a situation as individual behavior (unless consciously connected) would result in fragmentation and indifference, given that the intermediate results are not stable. https://www.un.org/en/model-united-nations/un-structure
} 


\begin{tabular}{|l|l|l|l|}
\hline & Indifference & Consciousness \\
\cline { 2 - 4 } & Fragmentation & 1 & 2 \\
\cline { 2 - 4 } Connection & 3 & 4 \\
\hline
\end{tabular}

Fig. 4 Outcomes of the C-Core

\section{Implanting the C-Core within the P-Puzzle}

Looking at the 4 components of the institutions that shape much of what we do, we notice the impact of their internal interplay on society. In this final part we apply the $C$-Core to the P-Puzzle by taking the example of the United Nations as a central supra-national institution. Aim is to illustrate how the $C$-Core may serve to align the pieces of the P-Puzzle within an entity. Moving from the center to the periphery each binomen is a combination of the $C$-Core outcome as it relates to the component of the institution.

What follows exaggerates and oversimplifies to bring out the logical arguments. Much good has been done by the $\mathrm{UN},{ }^{11}$ and thousands of fantastic and deeply committed people work in its ranks. This sub-section does not deny or diminish the achievements that were made. Rather it is an attempt to contribute certain questions that must be asked now.

\section{Priorities \& Completion}

Since collective welfare conditions individual wellbeing, the priorities chosen for and within each dimension must be geared towards the gradual completion (= optimization) of society.

People around the world are in acute need of help, and the UN is not fit to offer it. The Pandemic has brought to light not only divides within and between countries, but inside of the global body that was created to pacify and stabilize it.

Since the World Health Organization (WHO) declared the Pandemic on March $10^{\text {th }} 2020$, a wide range of international dignitaries, including UN Secretary-General António Guterres and leaders from China and Estonia to Tunisia, France, and Russia, have vied with one another to fill the geopolitical vacuum, putting forward a succession of plans to address the health crisis. But each effort has met either stringent resistance or indifference; raising questions about the ability of the UN to function effectively. On April 2, 2020 a group of six countries (Ghana, Indonesia, Liechtenstein, Norway, Singapore, and Switzerland) secured support for the unanimous passage of a nonbinding resolution in the 193-member General Assembly that called

\footnotetext{
11 The United Nations (UN) has six main organs-the General Assembly, the Security Council, the Economic and Social Council, the Trusteeship Council, the Secretariat, and the UN Security Council. In addition, there are various programs such as the UN Development Programs (UNDP), organizations like the World Health Organizations (WHO) and funds like the World Food Program (WFP) or the United Nations Children's Fund (UNICEF). The mandate of the UN is both political and oriented towards development and humanitarian aid. For further details see (United Nations, retrieved 2020) https://www.un. org/en/model-united-nations/un-structure
} 
for "intensified international cooperation to contain, mitigate and defeat" the coronavirus. In 2021 these words are yet to see action follow. Both the political and the programmatic branch of the UN Family faces a sensitive transition.

COVID-19 comes at a time that looks like the pinnacle of an evolution that led over the years to a transition from the hands-on approach that marked people, policies and programs during the early years of the UN, towards paper prioritization. The present questions are not geared towards criticism but optimization. Strong advocacy, quality data gathering, and technical guidance are essential; and maybe this crucial period in the UN's existence confirms that these features are indeed the organizations strongest assets in the twenty-first century. If that is the case it may be time to review and relinquish some of the other domains that were part of the original set-up and have outlived their time. Unveiling the UN's tremendous power to influence, inspire, and ignite change in the World requires candid internal changes. The goal must be to realign the institution with its original mission, the core of its creation. The WHY is not up for discussion, but WHAT, WHERE and how it is pursued by WHOM.

The values that underpin the UN's priorities are today just as valid as they were after World War II. ${ }^{12}$ But the World has changed, as everything always does and will. To re-align the ideals expressed in the UN's Charter with its action, the modus operandi of this institution that is meant to guard and promote the values that are enshrined in its Charter must evolve. This requires human beings.

\section{People \& Compassion}

Since humanity is a collection of people, the human thread is the rope that strangles or strengthens society. Compassion is the foundation that must be revived.

COVID-19 offers the UN an opportunity to step back and adopt a compassionate perspective of itself and of those whom it was meant to protect. Since its staff, like everyone else, is affected by COVID-19, directly or indirectly, the situation may inject the shared workspace with genuine human empathy. Having a secure job and solid salary means that most UN staff are not dramatically affected by the economic impact of the crises. However, they are not shielded from the mental toll of the situation, nor from the physiological consequences of the Virus itself. These circumstances placed the people in the organization into the same space of collective suffering as those outside.

Compassion is a human feature that enables supra-national organizations that were created to serve the world to fulfill their mandate. Some staff of international aid organizations, in particular national staff in low-income countries, do come from poor families and have grown up in precarious circumstances; yet the majority of those who enter the

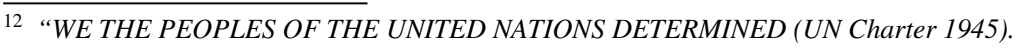

to save succeeding generations from the scourge of war, which twice in our lifetime has brought untold sorrow to mankind, and.

to reaffirm faith in fundamental human rights, in the dignity and worth of the human person, in the equal rights of men and women and of nations large and small, and.

to establish conditions under which justice and respect for the obligations arising from treaties and other sources of international law can be maintained, and

to promote social progress and better standards of life in larger freedom. [...] 
UN and other major aid organizations grew up in families that could afford at the minimum their food, care, and education. The need of professional, qualified staff is a valid justification of the prevailing recruitment profiles. However, technical know-how without human compassion is an empty promise. The Humanitarian system is not listening to people in crises' (Lowcock, Coordinator of UN Relief Operations; in Wintour 2021).

COVID-19 opens the door for those inside of aid organizations to step out of their bubble and into the shoes of those who are supposed to benefit from their help. The crisis impacted everyone in one way or another, it may thus serve at least as an emotional equalizer. Now is the time to reach out and re-establish human connection. Starting with Compassion for oneself and others. By acting in precisely the way we want to see happen around us we can take the first concrete step in a new direction. It sounds simplistic but it is pragmatic and concrete. Wherever we sit we can plant the seed of a circle of compassion that expands. Being part of supra-national institutions individual staff members can put the seed of a global circle, which grows from the core of those institutions into the world.

\section{Positions \& Creativity}

Since positions are meant to render institutions more efficient and effective, they must be (re)conceived with a creative spirit to be adequate for the challenge at stake.

The new status quo is radically different from the pre-COVID-19 situation. Responding to the unfolding scenario requires creativity and credibility. To be or become relevant aid institutions must adjust to the new setting, quickly. To survive in an international setting of reduced funding ingenuity is required. The need to prove added value accelerates the appetite for accountability that had been growing already before COVID-19. Efficiency and results-based implementation had inched into an ever more dominant place within the relationship of donors and aid agencies over the past decade. Aid institutions can seize COVID-19 as a momentum for candid internal conversations. An honest review of how they operate, and whether this is still in line with the needs of the world they are meant to serve, is overdue. It is not a question of judging or self-flagellating; but about honestly assessing and internally recognizing strength and lack thereof. The results of such self-assessment can be tackled only by creativity.

One example might be a radical review of the need to be present everywhere physically. The experience of COVID-19 might serve to reflect differently on the place, size, and necessity of offices in countries where the role of the aid organization is limited to technical guidance and advocacy. The caveat of this logic is that it invites parachuted blueprint approaches and disconnected advice. Transitioning from a national presence with the implementation of programs everywhere, to a selective presence in places where specific types of expertise are required; to a gradual phasing out with remaining focus locations that are of strategic importance for e.g. monitoring, technical advice on international standards, etc., might be an option. To make this workable and still maintain/build a strong connection with local realities, such a transition would have to be accompanied by the expansion and strengthening of local partnerships.

Compared to the present-day approach these partnerships could be anchored in more genuine cooperation (as opposed to implementation relationships). Guided by 
an understanding of mutual interest, the design and nurturing of a 'glocal' network is needed, a synthesis of the best that local and global attitude and action, experience and expertise, resources and resourcefulness have to offer. A collective effort that is pursued with a local heart (compassion for local needs) and a globalized mind (international sharing of lessons learned, best practices, and cross-border expertise) represents the modus operandi that is needed in the present, quickly evolving context of aid.

Maybe it is time to radically reduce the number of staff on the ground dedicated to delivering services (which should be provided by governments) and to benefit from technology to set-up small pools of experts who support local institutions in line with the realities in that place. Substantial savings would ensue to fund programs in locations that are more in need. Months of remote working arrangements put out the question whether large headquarters in cities with expensive housing prices (New York, Geneva, Rome, Vienna, Tokyo, Paris, Berlin) are still in touch with times and needs. Which leads to the next question. More efficient ways to operate could lead to a reduction of staff - getting more done with the same funding and less people. Cost-savings deriving from priorityshifts, and strategic reductions in infrastructure and staffing might contribute to fund the thematic needs that have come on top of the preexisting ones.

\section{Programs \& Cooperation}

Every player in the social game has a set of assets. Cooperation brings out the best added value of everyone, while maximizing the impact of programs geared towards people in need.

COVID-19 shows that everything is connected, and that only strong cooperation can get us out of the present conundrum. Systematic optimization of the different dimensions is needed to move us forward to something that is not like the past, but radically different, and better.

Like national governments, the United Nations were not ready to a disaster of this size and scope. Though it was predictable that sooner rather than later a global emergency was bound to happen, no agency was prepared. None had a contingency plan in place that would have allowed it to shift gears quickly. That imbalance of preparedness and adjustment has now found its counterpart in overcompensation; a state where everything and nothing is linked to the Pandemic. The need of institutional positioning and visibility in the context of an emergency that is in the public eye is not limited to COVID-19, nor the UN. It is a phenomenon that marks the entire aid sector and can be observed during every major emergency. Doing often equals being seen to be doing. To be perceived as active and efficient has direct impact on the funding that an aid agency receives from its donors. And funding affects what can be done, where, and by whom.

The UN and its peers face today not only the radically changed reality that derives from COVID-19, but also the swamp of open questions about development and humanitarian assistance that predates it. They must contribute to solve the global social conundrum that falls within their mandate and fix their internal conundrum. Their institutional identity crisis is the counterpart of the overall trial faced by Society.

Beyond the pain, COVID extended an invitation to look at a new reality from a fresh perspective. This perspective must include Compassion for our respective and 
collective past, Creativity to address the present and conscious Cooperation to move gradually towards future Completion. In the best-case scenario, individuals around the world, no matter the sector they are involved yet - yet starting with those who are professionally committed to social change agendas, anchor 'their' institution in the C-Core: Priorities reflect vision and values, which help the entity and its members to continually strive towards Completion - or the optimization of all available resources at the service of its purpose. Competition for resources and recognition is replaced by a spirit of solidarity which permeates the internal working atmosphere, as well as the interaction with other players in the sector. People are motivated by Compassion for the people whom they serve as part of their job, as much as for themselves and their colleagues. Their personal purpose is aligned with the mission of their employer; thus, they entertain harmonious social relationships because they have found peace inside. Rather than a state of emotional concussion the daily behavior of staff mirrors their human values. Based on honest insight into the weaknesses and strengths of the institution, Positions are the result of a constant strive for pragmatic Creativity that brings out the best in everyone. Blind compliance with rules is challenged at all levels. Programs are geared towards Cooperation in view of mutual complementarity. Behold of the needs of the target audience, areas of action are systematically selected to maximize the added value of the resources at hand; instead of closing-down the institutional horizon to focus on short-term internal benefits.

\section{Concluding Remarks: Something Different it Needed}

2020 showed that the modus operandi of the past is inadequate. COVID-19 confronts us with the need for something different. Because doing more of the same brings more of the same.

The prevailing systemic social paradox can only be addressed by planting the $C$-Core at the center of human interaction. Those who presently constitute the C-Suite in an institution must rethink their role in the status quo, as must everyone else. Today we - each of us, have the possibility to not merely tackle a crisis, but to lay the ground for a new social contract, the foundation of a different tomorrow.

Supplementary Information The online version contains supplementary material available at https://doi. org/10.1007/s42413-021-00110-0.

\section{Declarations}

Conflict of Interest On behalf of all authors, the corresponding author states that there is no conflict of interest.

\section{References}

Bicchieri, C. (2016). Norms in the wild. How to Diagnose, measure, and change social norms. Oxford University Press.

Biccheri, C., \& Xiao, E. (2008). Do the right thing: But only if others do so. Retrieved March 2020 from https://onlinelibrary.wiley.com/doi/abs/10.1002/bdm.621. 
Darley, J. M., \& Latané, B. (1968). Bystander intervention in emergencies: Diffusion of responsibility. Journal of Personality and Social Psychology, 8(4, Pt.1), 377-383. https://doi.org/10.1037/h0025589.

Doidge, N. (2011). The Brain that changes itself. Carlton North Vic.

Doidge, N. (2015). The brain's way of healing: remarkable discoveries and recoveries from the frontiers of neuroplasticity. New York, NY: Viking Press.

Easterly, W. (2007). The white man's burden: why the west's efforts to aid the rest have done so much Ill and so little good. Penguin Books; Reprint edition.

Festinger, L. (1957). A theory of cognitive dissonance. California: Stanford University Press.

Frankl, V. (1946). Men's search for meaning. Republication by Paperback (2006).

French, J. R., \& Raven, B. (1959). The bases of social power. Studies in social power. D. Cartwright (Ed.), Research Center for Group Dynamics, Univ. of Michigan.

Gordon, J. (2009). Unstuck. Your guide to the seven-stage journey out of depression. Penguin Books; Reprint edition (May 26, 2009).

Gräbner, C., \& Ghorbani, A. (2019). Defining institutions - A review and a synthesis, ICAE Working Paper Series, No. 89, Johannes Kepler University Linz, Institute for Comprehensive Analysis of the Economy (ICAE), Linz.

Haidt, J. (2006). The moral roots of liberals and conservatives. TED. Retrieved (Aug 2020) https://rb.gy/ feplgt.

Hodgson, G. (2006). What are institutions? Journal of Economic Issues, 40(1), 1-25.

Ibarra, H. (2015). Act like a leader, think like a leader. Harvard Business Review Press.

Kahneman, D. (2007). Thinking fast and slow. Macmillan Palgrave.

Knight, J. (1992). Institutions and Social Conflict. Cambridge Universisty Press.

Kropotkin, P. (1998). Mutual aid: A factor of evolution. - L.: Freedom Press.

Lama, D. H.H. the Fourteenth (1990). Policy of kindness: An anthology of writings by and about the Dalai Lama. Shambhala. p. 112.

Maslow, A. H. (1943). A theory of human motivation. Psychological Review., 50(4), 370-396.

Maslow, A. H. (1996). Critique of self-actualization theory. In E. Hoffman (Ed.), Future visions: The unpublished papers of Abraham Maslow (pp. 26-32). Thousand Oaks, CA: Sage.

Michalos, A. C. (2017). Encyclopedia of quality of life and well-being research: social sciences (Wellbeing \& Quality-of-Life). Sam Ficher publications.

Minujin, A., \& Grondona A. (2013). Poverty, needs and rights: Definitions in dispute. No. 22 of Voces en el Fénix.

North, D. C. (1991). Institutions. Journal of Economic Perspectives, 5(1), 97-112.

Nowak, M. (2011). SuperCooperators: Altruism, evolution, and why we need each other to succeed, with Roger highfield. Martin Free Press.

Office of the United Nations High Commissioner for Human Rights (OHCHR) and World Health Organization (WHO). (2000). The Right to Health. Factsheet No.31.

Peal, N. V. (1952). The Power of Positive Thinking. Prentice Hall.

Pisano, G. P. (2019). The hard truth about innovative cultures. Creativity can be messy. It needs discipline and management. HBR. Retrieved March 2020 from https://hbr.org/2019/01/the-hard-truthabout-innovative-cultures.

Ro, C. (2020). Coronavirus: why some racial groups are more vulnerable. BBC (April 2020). Retrieved April 2020 from https://bbc.in/3iMwfPM.

Roy, A. (2020). The pandemic is a portal. Financial Times (April 2020). Retrieved April 2020 from https://on.ft.com/30PWePS.

Seligman, M. E. P. (2011). Flourish: A visionary new understanding of happiness and well-being. Free Press.

Singh, A. (2018). Organizational power in perspective.https://doi.org/10.1061/(ASCE)LM.1943-5630. 0000018 .

Stewart, F. (2013). Approaches towards inequality and inequity: Concepts, measures and policies, Office of Research Discussion Paper No.2013-01, UNICEF Office of Research, Florence.

Stiglitz, J. (2012). The Price of Inequality. Allen Lane.

Sustainable Development Goal website (SDG). (2020). Retrieved March 2020 from https://sustainabl edevelopment.un.org/sdg17.

Thaler, R. H., \& Sunstein, C. R. (2009). Nudge: Improving decisions about health, wealth, and happiness. Rev. and expanded. Penguin Books.

Thijssen, P. (2012). From mechanical to organic solidarity, and back: With Honneth beyond Durkheim. European Journal of Social Theory, 15, 454-470. 
United Nations Structure. Retrieved March 2020 from https://www.un.org/en/model-united-nations/unstructure.

Universal Declaration of Human Rights (UDHR). (1948). Retrieved 2020 from https://www.un.org/en/ universal-declaration-human-rights/.

Vandemoortele, J. (2018). From simple-minded MDGs to muddle-headed SDGs. Tandfonline. Retrieved February 2020 from https://www.tandfonline.com/doi/full/10.1080/21665095.2018.14796472018.1479647.

Vandemoortele, J. (2019). The open-and-shut case against inequality. Development Policy Review. Retrieved January 2020 from https://doi.org/10.1111/dpr.12484.

Walther, C. (2014). Le Droit au Service de l'Enfant. University print - Aix-en-Provence/Marseille.

Walther, C. (2020a). Development, humanitarian aid and social welfare. Social change from the inside out. Palgrave/Springer Nature.

Walther, C. (2020b). Humanitarian work, social change and human behavior. Compassion for change. Palgrave/Springer Nature.

Walther, C. (2020c). Development and connection in the times of COVID. Corona's call for conscious choices. Palgrave/Springer Nature.

Walther, C. (2021). Technology, social change and human behavior. Influence for Impact. Palgrave/ Springer Nature.

Wilkinson, R., Pickett, K. (2009). The spirit level: Why more equal societies almost always do better. Allen Lane.

Wintour, P. (2021). Humanitarian system not listening to people in crises, says UN aid chief. The Guardian. Retrieved April 2021 from https://www.theguardian.com/global-development/2021/apr/21/ humanitarian-failing-crisis-un-aid-relief.

World Health Organization (2019). WHO launches new report on global tobacco use trends. (Dec 2019). Retrieved from https://www.who.int/news-room/detail/19-12-2019-who-launches-new-report-onglobal-tobacco-use-trends.

Publisher's Note Springer Nature remains neutral with regard to jurisdictional claims in published maps and institutional affiliations. 